\title{
Numerical modeling on homogeneous charge compression ignition combustion engine fueled by diesel-ethanol blends
}

\author{
H.Hanafi ${ }^{1, a}$, M.M.Hasan ${ }^{1}$, M.M.Rahman ${ }^{1,2}$, M.M.Noor ${ }^{1,2}$, K.Kadirgama $^{1,2}$ and D. Ramasamy ${ }^{1,2}$ \\ ${ }^{1}$ Automotive Engineering Research Group, Faculty of Mechanical Engineering, Universiti Malaysia Pahang, 26600 Pekan, Pahang, \\ Malaysia \\ ${ }^{2}$ Automotive Engineering Centre, Universiti Malaysia Pahang, 26600 Pekan, Pahang, Malaysia
}

\begin{abstract}
This paper investigates the performance and emission characteristics of HCCI engines fueled with oxygenated fuels (ethanol blend). A modeling study was conducted to investigate the impact of ethanol addition on the performance, combustion and emission characteristics of a Homogeneous Charge Compression Ignition (HCCI) engine fueled by diesel. One dimensional simulation was conducted using the renowned commercial software for diesel and its blend fuels with 5\% (E5) and 10\% ethanol (E10) (in vol.) under full load condition at variable engine speed ranging from 1000 to $2750 \mathrm{rpm}$ with $250 \mathrm{rpm}$ increment. The model was then validated with other researcher's experimental result. Model consists of intake and exhaust systems, cylinder, head, valves and port geometries. Performance tests were conducted for volumetric efficiency, brake engine torque, brake power, brake mean effective pressure, brake specific fuel consumption, and brake thermal efficiency, while exhaust emissions were analyzed for carbon monoxide (CO) and unburned hydrocarbons (HC. The results showed that blending diesel with ethanol increases the volumetric efficiency, brake specific fuel consumption and brake thermal efficiency, while it decreases brake engine torque, brake power and brake mean effective pressure. In term of emission characteristics, the $\mathrm{CO}$ emissions concentrations in the engine exhaust decrease significantly with ethanol as additive. But for HC emission, its concentration increase when apply in high engine speed. In conclusion, using Ethanol as fuel additive blend with Diesel operating in HCCI shows a good result in term of performance and emission in low speed but not recommended to use in high speed engine. Ethanol-diesel blends need to researched more to make it commercially useable.
\end{abstract}

\section{Introduction}

In the past decades a diesel engine has turned out to be the most standout fuel effective energy. Diesel engines have many advantages, for example simplicity, high performance, less maintenance, low fuel costs, low fuel consumption, high compression ratio, high power/weight ratio and durability [1]. But, its disadvantages are the exhaust of diesel engines are one of the major contributions to the air pollution problem, such as particulate matter, hydrocarbons, and carbon monoxide emissions [2]. The high flame temperatures that occur at the close-to-stoichiometric auto-ignition regions are the main contributor of hazardous emissions while the mixing-controlled burning of the bulk fuel contributes to the formation of soot. A reduction in $\mathrm{NO}_{\mathrm{x}}$ emissions can be achieved by decreasing the combustion temperatures to below $1800 \mathrm{~K}$ [3] while the soot formation can be decreased by improving the homogeneity of the air-fuel mixture.

In order to solve the diesel engine disadvantages, researchers are now concentrating on new mode of combustion in internal combustion engine. HCCI is an alternative operating mode for an internal combustion engine and is considered as one potential solution to solve this problem $[4,5]$ besides that HCCI also can operated on wide range of fuel [3]. HCCI engines operates at higher thermal efficiency as high as $50 \%$ [6] than gasoline and diesel engines [7,8] with similar displacement volume, while it also emits ultra-low particle matter (PM) and nitrogen oxides (NOx)

\footnotetext{
a Corresponding author: hasrulazmi.h@gmail.com
}

emissions [9]. These emission reductions are achieved by physically separating the injection events from the onset of combustion, therefore makes ignition delayed long enough to ensure a lean and nearly-homogenous air-fuel mixture.

Using HCCI combustion, a wide range of fuel can be used. Ethanol is one of the next generation renewable biofuel that can be used in HCCI. It is biodegradable, low in toxicity and less polluted compared to fossil fuels [10]. Ethanol are selected for this study since they are promising alternatives in order to substitute conventional petroleum fuels in next-generation of internal combustion engines (ICEs) [11]. Ethanol can be produced from different types of sources, mainly from carbon based feed stocks. Therefore usage of alcohols in engines is another way to reduce energy resource depletion by using fossil fuels, and improve the implementation of HCCI combustion mode [12]. It also another significant research purposes to combine the advantages of HCCI combustion mode using alternative renewable oxygenated fuels. Tongroon et al. [12] found that methanol showed fastest and earliest auto-ignition, followed by ethanol using optical methods investigated in HCCI combustion mode .Christensen et al. [13] used a lean air-fuel mixture for HCCI engine that operated unthrottled, producing an ultra-low $\mathrm{NO}_{\mathrm{x}}$ emission result.

Later on, Mack et al. [14] used wet ethanol in HCCI combustion mode and reported that increasing water concentration in ethanol reduced the in-cylinder maximum pressure rise and improved energy balance, but increased the emission of $\mathrm{HC}$ and $\mathrm{CO}$. Viggiano and 
Magi [15] modeled a multidimensional numerical model with a kinetic reaction mechanism for ethanol oxidation and $\mathrm{NO}_{\mathrm{x}}$ formation, and found that $\mathrm{CO}$ emissions are strongly related to inhomogeneities in the near walls of the combustion chamber. Another investigations was done and found out that the tendency of alcohols to autoignite relatively earlier cause lower emission [16, 17]. Only few literature results are done on the modeling approach of ethanol fueled engines. Sjoberg and Dec [18] develop a multi-zone model ethanol-chemical kinetics mechanism in a single cylinder HCCI engine fueled using pure ethanol (100\%). Splitter et al. [19] develop computational fluid dynamics (CFD) modeling on premixed charge compression ignition (PCCI) engine fueled by early injected pure ethanol and on dual-fuel (ethanol-diesel fuel) engine .

The above review shows not much research has been done from a numerical point of view on using alcohol fuels in HCCI engine mode. More studies need to be done to provide deeper insight and greater understanding on HCCI combustion and emission characteristics using alcohol fuels. The objective of this paper is therefore to numerically investigate performance, combustion and emission characteristics in a HCCI engine using diesel-ethanol blend.

\section{Numerical modeling}

In this paper, a one-dimensional (1-D) simulation was done for one cylinder, four strokes and direct ignition (DI) engine. The details of the engine parameters are shown in Table 1 . The modeling was performed using the 1-D engine in simulation software. A one cylinder, four stroke, direct ignition (DI) engine was modeled to simulate the engine performance and emissions. The numerical model consists of intake and exhaust systems, cylinder, head, valve and port geometries i.e. crank angle degree ( ${ }^{\circ} \mathrm{CA}$ ). The complete model is shown in Figure 1. Operational parameters such as cam phasing, combustion phasing and duration, and air-fuel ratio were determined by built-in look-up table maps based on load and speed of the simulation case. The simulation was done using different engine speed (rpm); 1000, 1250, 1500, 1750, $2000,2250,2500$ and 2750 with two types of dieselethanol blends; E5 and E10. The properties of fuels used in this research are shown in Table 2.

In order to distinguish between Compression Ignition (CI) and Spark Ignition (SI) engine model, this modeling was added with chemical reaction obtain from Lawrence Livermore National Laboratory website. A chemical reaction consists of diesel and ethanol was added before simulation was done in order to get the results. In order to make sure the modeling are correct, this model was verified with other researcher's experimental result which will be discussed later in this paper.

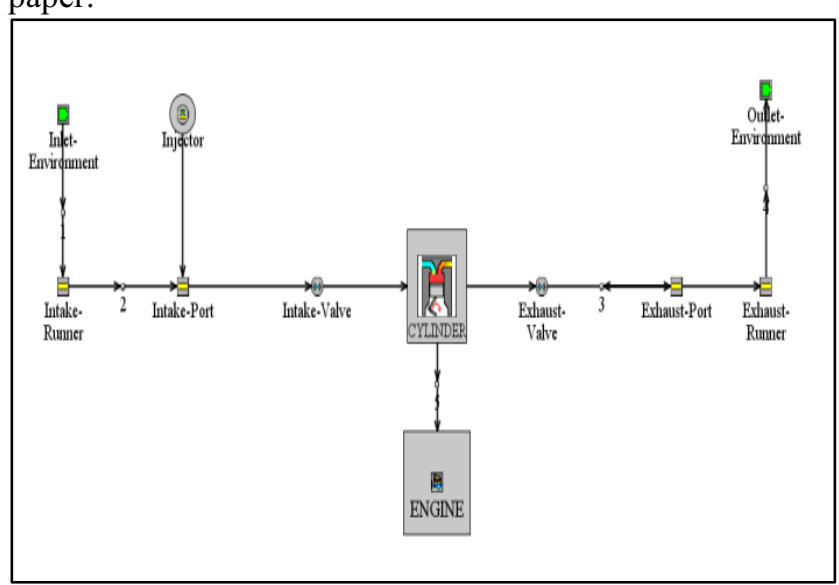

Figure 1. Numerical model setup

Table 1. Engine model specifications

\begin{tabular}{ll}
\hline Engine parameters & Value \\
\hline Type & $\begin{array}{l}\text { 1-cylinder, air cooled, } \\
\text { overhead valve, } \\
\text { direct injection }\end{array}$ \\
Bore $(\mathrm{mm})$ & 87.5 \\
Stroke $(\mathrm{mm})$ & 110 \\
Displacement $(L)$ & 1.583 \\
No. of cylinders & 1 \\
Compression ratio & 17.5 \\
Connecting rod length $(\mathrm{mm})$ & 150 \\
Piston pin offset $(\mathrm{mm})$ & 1 \\
Intake Valve Open $\left({ }^{\circ} \mathrm{CA}\right)$ & 351 \\
Intake Valve Close $\left({ }^{\circ} \mathrm{CA}\right)$ & -96 \\
Exhaust Valve Open $\left({ }^{\circ} \mathrm{CA}\right)$ & 125 \\
Exhaust Valve Close $\left({ }^{\circ} \mathrm{CA}\right)$ & 398 \\
\hline
\end{tabular}

\section{Governing equations and flow models}

One dimensional flow equation is solved with and across the pipes. A pipe can be further discretized into many nodes, and the flow equations are solved at node level. Since it is one dimensional flow, variables are uniform at pipe cross section. Each scalar variable is assumed to be uniform over each node, and each vector variable is calculated at each boundary. Accordingly, the equations that involve in this modeling are: 
Table 2. Fuel properties of diesel and ethanol [20]

\begin{tabular}{lcccc}
\hline Fuel properties & Diesel & Ethanol & E5 & E10 \\
\hline Chemical formula & $\mathrm{C}_{12} \mathrm{H}_{26}-\mathrm{C}_{14} \mathrm{H}_{30}$ & $\mathrm{C}_{2} \mathrm{H}_{5} \mathrm{OH}$ & - & - \\
Density at $20^{\circ} \mathrm{C}(\mathrm{kg} / L)$ & 0.8485 & 0.7893 & 0.8385 & 0.8308 \\
Low calorific value $(\mathrm{kJ} / \mathrm{kg})$ & 44514.6 & 26,800 & 43631.8 & 43192.5 \\
Viscosity at $40{ }^{\circ} \mathrm{C}\left(\mathrm{mm}^{2} / \mathrm{s}\right)$ & 5.614 & 1.2 & 5.5343 & 5.4564 \\
Cetane number & 50 & $\sim 8$ & - & 44.2 \\
Flash point $\left({ }^{\circ} \mathrm{C}\right)$ & 53 & 14 & 24 & 25 \\
Boiling point $\left({ }^{\circ} \mathrm{C}\right)$ & $180-360$ & 78 & - & - \\
Latent heat of evaporation $(\mathrm{kJ} / \mathrm{kg})$ & 250 & 840 & - & 43.4 \\
Stoichiometric air-fuel ratio & 15 & 9 & - & - \\
Oxygen $(\%$ by weight) & 0 & 34.8 & - & - \\
Self-ignition temperature $\left({ }^{\circ} \mathrm{C}\right)$ & 254 & 363 & - & - \\
\hline
\end{tabular}

Continuity : $\quad \frac{d m}{d t}=\sum_{\text {boundaries }} \rho A v$

Where, $\rho=$ density

$v=$ speed

$A=$ area

Energy:

$\frac{d(m e)}{d t}=p \frac{d V}{d t}+\sum_{\text {boundaries }}(\dot{m} \times H)-$
$h_{g} A\left(T_{\text {gas }}-T_{\text {wall }}\right)$

Where, $\dot{m}=$ mass flow rate

$p=$ pressure

$A=$ area

$H=$ height

$h_{g}=$ head loss

$T_{\mathrm{g}}=$ temperature of gas

$T_{\text {wall }}=$ Temperature of wall

Momentum:

$\frac{d(\rho A v)}{d t}=$

$\frac{d p A+\sum_{\text {boundaries }}(\rho A v \times v)-C_{f} \frac{\rho v^{2}}{2} \frac{d x A}{D}-C_{p}\left(\frac{1}{2} p v^{2}\right) A}{d x}$

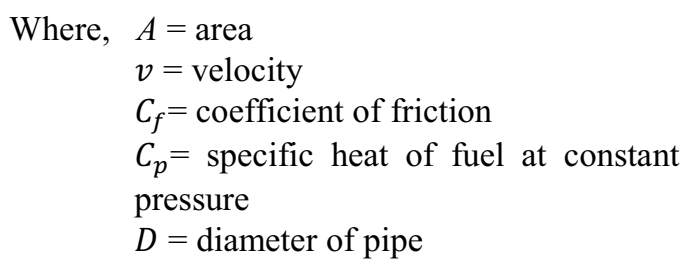

In this numerical modeling, friction across the pipe is considered. This friction is already set in the software used (built-in) to model the HCCI engine and not negligible. The friction loss factor is based on the Reynolds number and the surface roughness of the walls. In Laminar region when Reynolds number is less than 2000, $C_{f}=16 / R e_{D}$. In turbulent region, $C_{f}=$
$0.08 / R e_{D}^{0.25}$. When the surface is rough and the flow is not laminar, the friction coefficient is calculated below:

$$
C_{f_{\text {rough }}}=\frac{0.25}{\left(2 \log _{10}\left(\frac{D}{2 H}\right)+1.74^{2}\right)}
$$

Where, $\quad C_{f}=$ Coefficient of friction

$$
\begin{array}{ll}
D & =\text { Diameter of pipe } \\
H & =\text { Height }
\end{array}
$$

Volumetric Efficiency: defined as the ratio between the air mass flow into the cylinders from the intake manifold and the air mass theoretically inside the cylinders at the manifold temperature. As such, it measure the effectiveness of the air pumping system composed by the intake manifold, the inlet port and valve, and the cylinders [21] :

$$
\eta_{v}=\frac{\dot{m}_{a}}{\rho_{a} V_{d N / 2}}
$$

Where, $\rho_{a}=$ the inlet air density

$\dot{m}_{a}=$ the steady-state flow of air into the engine $V d=$ displacement volume

Brake Engine Torque: The measure of the engine's ability to apply power generation is called torque [22]. Torque is defined as force acting at a moment distance, their unit is $\mathrm{N}-\mathrm{m}$ or lbf-ft. The equation is expressed as below [23, 24]:

$$
2 \pi \tau=W_{b}=(b m e p) V_{d} / n
$$

Where, $\quad W_{b}=$ brake work of one revolution

$$
\begin{array}{ll}
V d & =\text { displacement volume } \\
n & =\text { number of revolutions per cycle }
\end{array}
$$

For a four-stroke cycle engine that takes two revolutions per cycle,

$$
\tau=(\text { bmep }) V_{d} / 4 \pi
$$

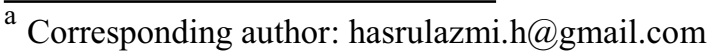


Brake Power: Power is defined as the rate of work of the engine. Brake power refers to the amount of usable power delivered by the engine to the crankshaft $[23,25]$. The equation is expressed as below:

$$
\begin{gathered}
\dot{W}=W N / n \\
\dot{W}=2 \pi N \tau \\
\dot{W}=(1 / 2 n)(m e p) A_{p} \bar{U}_{p} \\
\dot{W}=(m e p) A_{p} \bar{U}_{p} / 4
\end{gathered}
$$

$$
\text { Where, } \begin{aligned}
\mathrm{W} & =\text { work per cycle } \\
A_{p} & =\text { piston face area of all pistons } \\
\bar{U}_{p} & =\text { average piston speed } \\
\mathrm{n} & =\text { number of revolutions per cycle } \\
\mathrm{N} & =\text { engine speed }
\end{aligned}
$$

Brake Thermal Efficiency: The brake thermal efficiency of an engine is defined as the ratio of brake output power to input power and the brake power produced by an engine with respect to the energy contributed by the fuel [26]. The equation is expressed as below:

$$
\eta_{b t h}=\frac{\mathrm{bp}}{\text { mass of fuel x calorific value of fuel }}
$$

Brake Mean Effective Pressure: The brake mean effective pressure [27] is defined to measure engine performance and indicates an engine's capacity to produce power output over the full engine speed range. The equation is expressed as below:

$$
\begin{gathered}
\text { bmep }=w_{b} / \Delta v \\
\text { bmep }=2 \pi n \tau / V_{d}
\end{gathered}
$$

Where, $\Delta v=v_{b d c}-v_{t d c}$

Brake Specific Fuel Consumption: The fuel consumption characteristics of an engine are generally expressed in terms of specific fuel consumption in kilograms of fuel per kilowatt-hour. In engine tests, the fuel consumption is measured as a flow rate-mass flow per unit time. It measures how efficiently an engine uses the fuel supplied to produce work [28]. The equation is expressed as below:

$$
b s f c=\dot{m}_{f} / \dot{W}_{b}
$$

Where, $\dot{m}_{f}=$ rate of fuel flow into engine

\section{Model validations}

To further validate the applicability of the developed reaction mechanism for engine simulations, numerical simulations were performed and compared against the diesel engine experiments. Figure 2 (a) plots the incylinder pressure and Figure 2 (b) plots the in-cylinder temperature obtained from experiments done by [29] and our simulations, at a fixed engine speed of $1500 \mathrm{rpm}$ under full load conditions. As can be seen, the peak cylinder pressure and peak temperature timing are adequately reproduced, indicating that the important reaction pathways are very well represented. The predicted in-cylinder temperature are slightly higher and narrower than those calculated from the experimental cylinder pressure curves, suggesting that slightly higher burning rate is predicted by the developed reaction mechanism during the initial premixed burning phase.
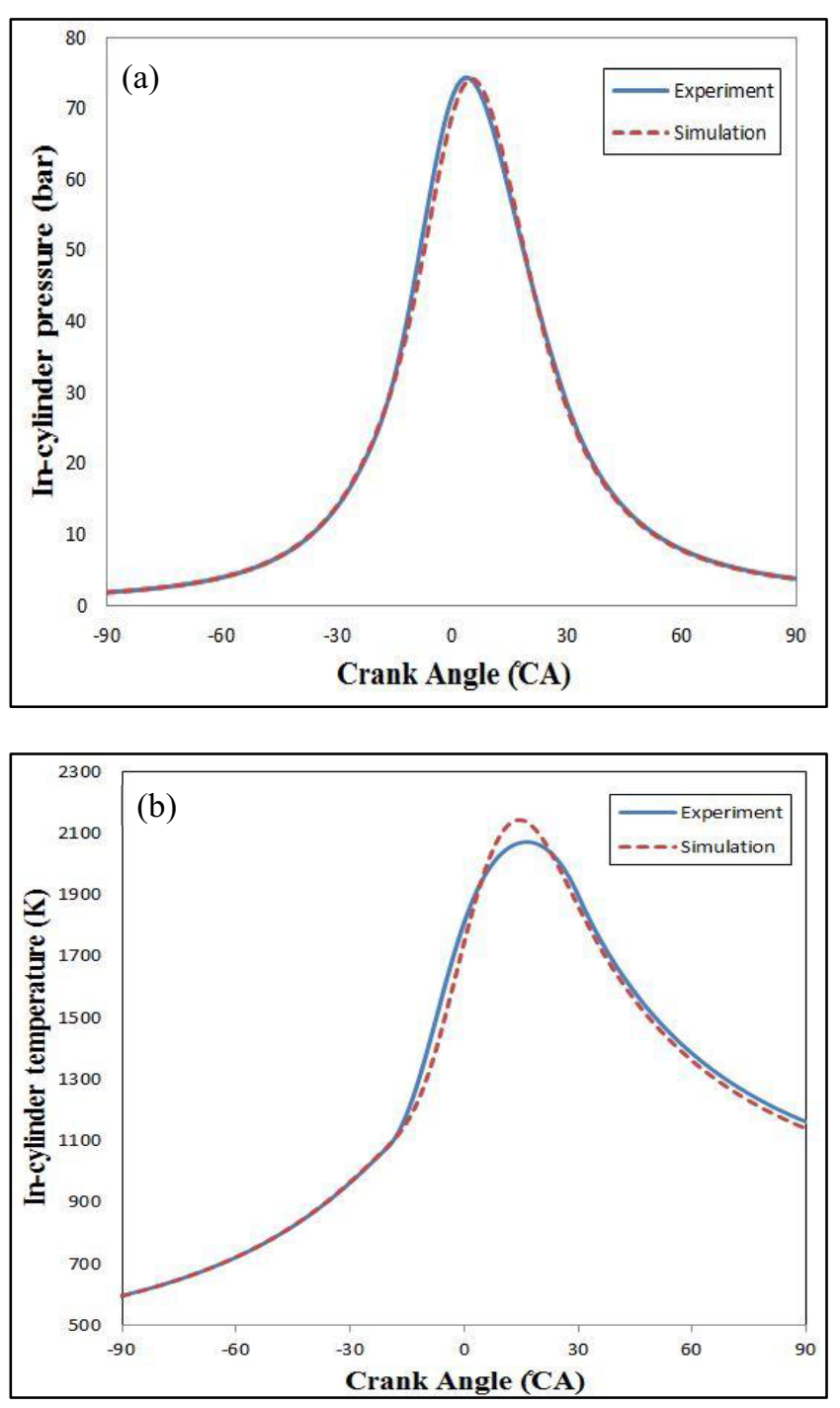

Figure 2. A comparison of simulated and experimental in-cylinder pressure (a) and temperature (b) under full load at $1500 \mathrm{rpm}$ engine speed.

\section{Results and discussion}

\subsection{Engine Performance}

The numerical results are presented for diesel, dieselethanol blends fueled in HCCI combustion at different engine speeds. Performance and emission characteristics are analyzed in each figure. 

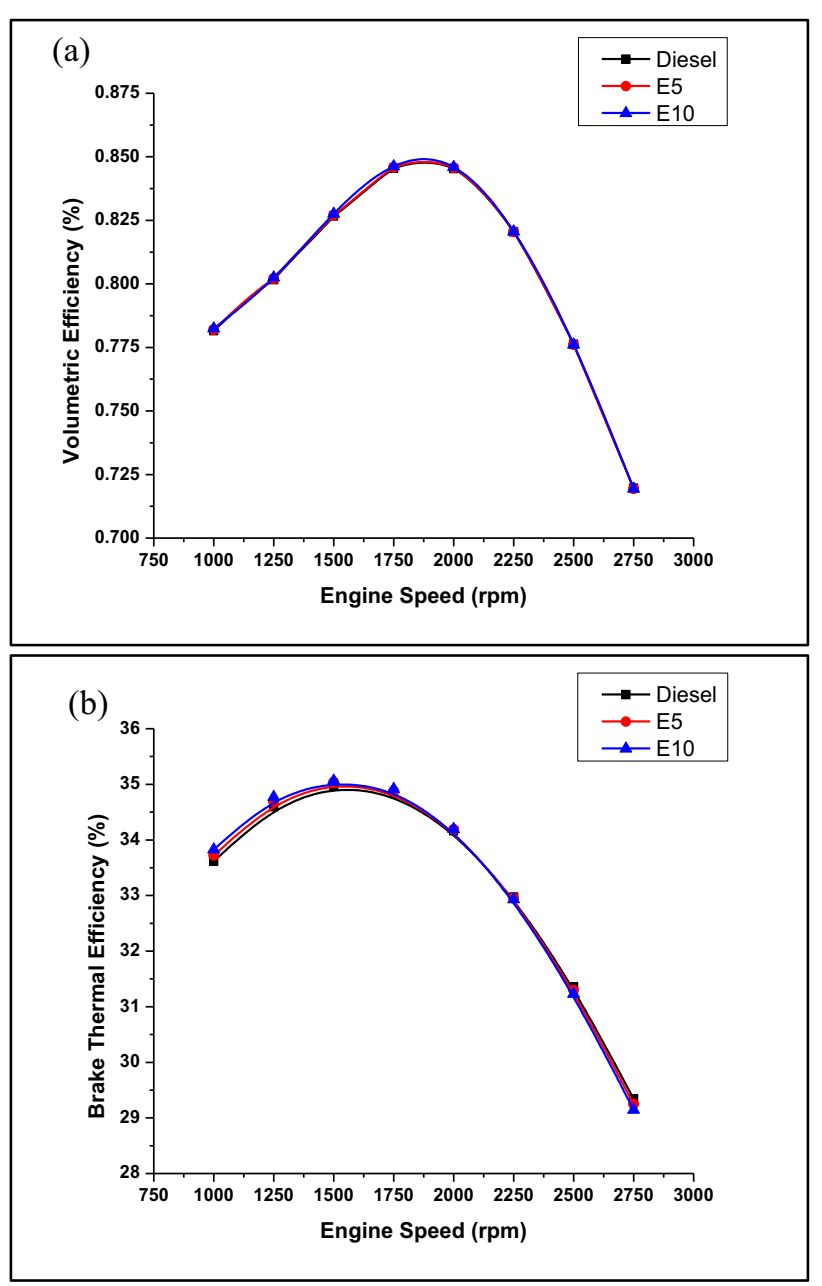

Figure 3. (a) Volumetric efficiency (b) Brake Thermal Efficiency against different engine speed

Figure 3(a) shows the result of volumetric efficiency at different speeds using 3 different types of fuels in HCCI engine. From Figure 3 (a), it can be seen that only slightest differences occur for each type of fuels. The highest volumetric efficiency happens at 1875 rpm for each test fuel. As the engine speeds increase, the volumetric efficiency decreases dramatically. This is because when the engine speed increase, the air have less time to goes inside the cylinder [30]. Hence, the amount of the air that fills the cylinder decrease and cause an incomplete combustion. It has been researched that when the ethanol amount use increases, the volatility and the latent heat of the fuel also increases [31], hence the volumetric efficiency also increased.

Figure 3 (b) shows the brake thermal efficiency (BTE) result. It show a decrease of BTE with engine speed as the amount of the ethanol amount in the blends increases. It can be seen from Figure 3 (b) that the E10 fuel gives highest efficiencies at $1500 \mathrm{rpm}$. The diesel fuel produced the lowest BTE during the slow engine speed. But as the speed goes higher, diesel fuel overtake the diesel-ethanol blends. The main reason for decrease of thermal efficiency with increase in blend ratio is shorter ignition delay which results in earlier start of combustion than for diesel. This increases the compression work as well as heat loss $[32,33]$ and thus reduces the efficiency $[34,35]$ of the engine.

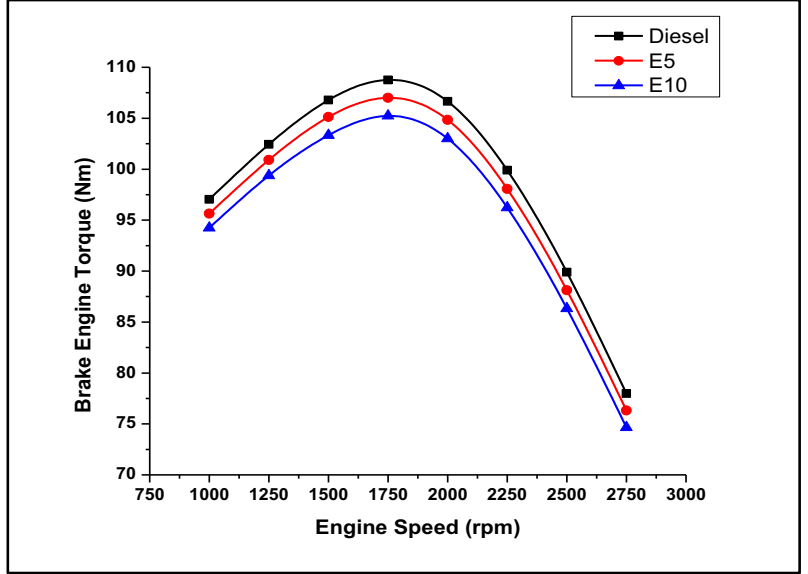

Figure 4. Brake engine torque against engine speed

Figure 4 shows the effect of engine speed and different blends of fuel on brake engine torque (BET) at different engine speeds. It is observed that at higher engine speed, BET decreasing. Diesel attained highest BET compared to E5 and E10 fuel. At higher engine speed, auto-ignition temperature is attained relatively earlier. BET obtained is significantly lower at fastest engine speeds condition. The possible explanation for this observation is as follows. At very fast engine speed (2750 rpm), the temperature in the combustion chamber is low, and the combustion efficiency is also low. As a consequence, large quantities of unburned hydrocarbons are emitted and lower BET is obtained. It is observed that BET is at peak at the $1750 \mathrm{rpm}$ for all 3 types of fuel used. It is also noticed that after $1750 \mathrm{rpm}$, BET starts decreasing. At fastest engine speed, knocking combustion starts, which cause increased heat transfer to the piston and cylinder walls [36], resulting in lower BET value.

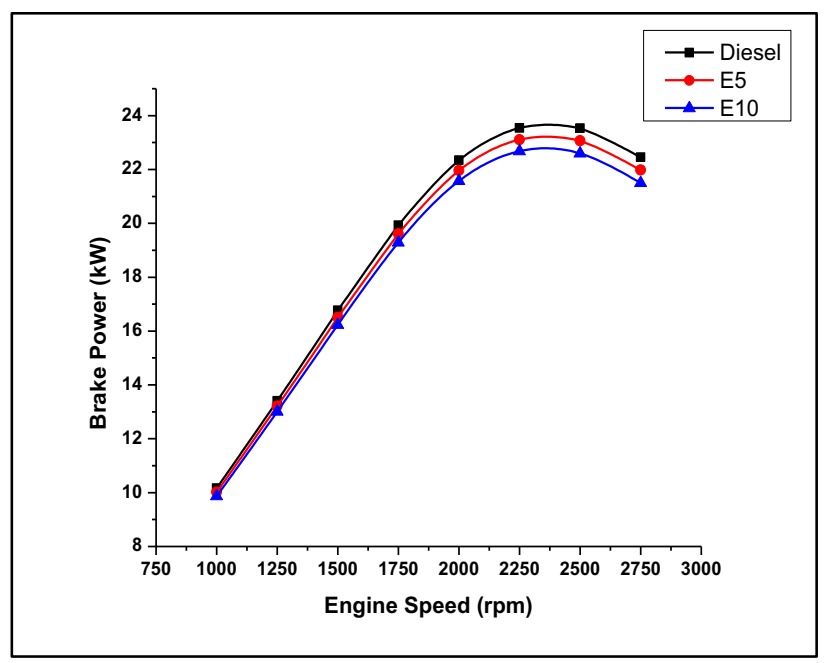

Figure 5. Brake power result against engine speed

Figure 5 shows the variation of brake power with increasing speed on the engine. It can be seen that diesel fuel alone still producing the highest brake power compared to the E5 and E10 fuel. Diesel-ethanol blends reduces engine power output as the portion of oxygenated compounds (ethanol) in the blends increases [37]. This is due to the low cetane number and calorific value and higher ignition delay of the blends, compared to diesel 
fuel [38]. Other researchers also found out that approximately $4.4-8.7 \%$ reduction in maximum power output by using diesel-ethanol blends compared to fossil diesel fuel [39]. Thus using these blends without any additives only will reduce engine power and torque output. These reduced torque and power can be improved and the combustion characteristics can also be optimized by using additives with these blends [40]. If no additives are used, then the portion of the ethanol/bioethanol should be kept as low as possible.

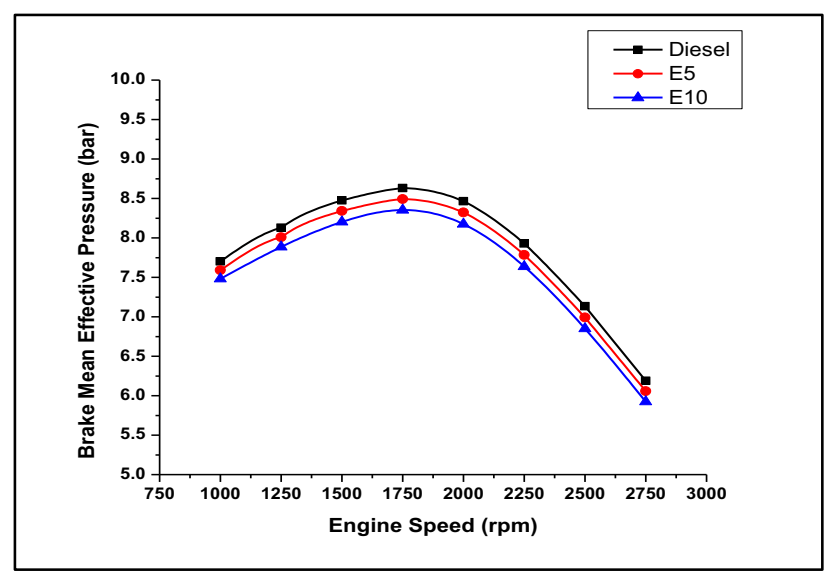

Figure 6. Brake mean effective pressure against engine speed

The result of brake mean effective pressure (BMEP) for 3 types of fuels is presented in Figure 6. As shown in Figure 6, the BMEP decrease using ethanol as additives with diesel fuels. E10 shows the lowest BMEP value throughout all engine speeds with diesel producing highest BMEP result. Higher maximum BMEP means higher stresses and temperatures in the engine hence shorter engine life or bulkier engine. As ethanol has lower cetane value, longer ignition delay and high auto ignition temperature, the BMEP decrease along with increase of engine speeds. This leads to reduced ignition delay. The lower boiling point of ethanol makes it to evaporate as the diesel gets ignited. As a result of the vaporized ethanol, the mixture burns more rapidly than diesel. This reaction results in better engine performance. The longer ignition delay of ethanol results in diffusive end burning and drops in BMEP value.

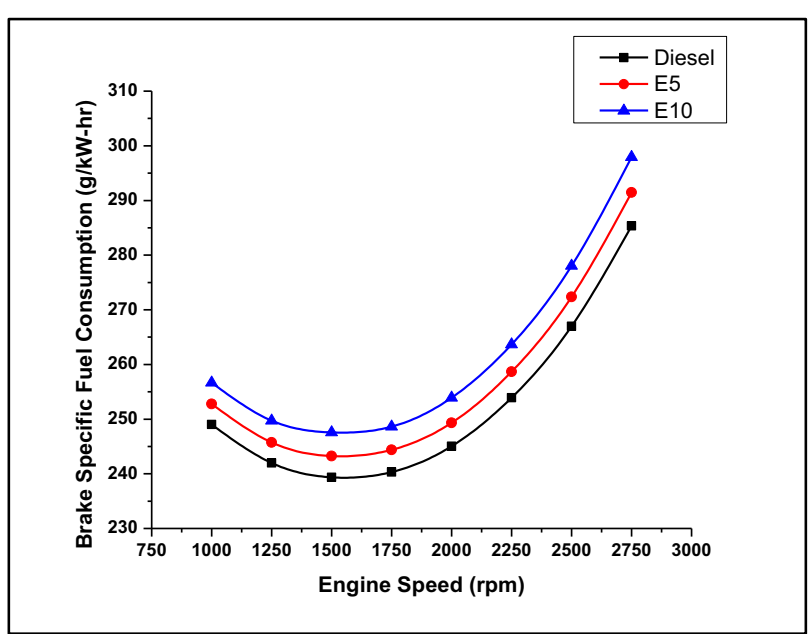

Figure 7. Brake specific fuel consumption against engine speed

The relationship between engine speed and brake specific fuel consumption (BSFC) for different diesel/ethanol blends are shown in Figure 7. The figure shows that the BSFC trend for diesel and diesel-ethanol blends are similar in nature. In all cases, diesel fuel shows the lowest BSFC as compared to diesel-ethanol blends because diesel has higher heating value and requires a lower mass than the other fuels to extract the same engine output. In general, the BSFC increased with increasing ethanol content in blend fuel. This is due to the fact that the low heat value of ethanol is about $2 / 3$ of that of diesel [41]. The other reason is the incomplete combustion due to the ignition delay of ethanol-diesel blend fuel. Overall, ethanol addition in diesel does not create a significant change in BSFC.

\subsection{Exhaust Emissions}

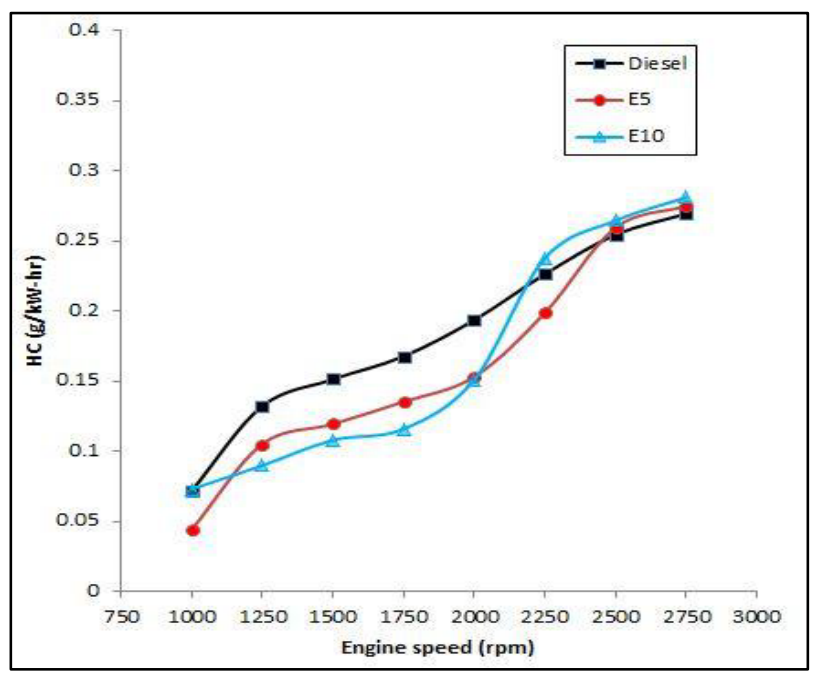

Figure 8. Hydrocarbon against engine speed

Figure 8 shows the results of hydrocarbon (HC) emission with different engine speed using 3 different types of fuels. This higher $\mathrm{HC}$ might be caused because of higher amounts of single hydrogen radicals in alcohol-diesel fuel in-cylinder charge. It is confirmed by investigation done by others. High content of alcohol in diesel-alcohol 
blends contributes to increase in $\mathrm{HC}$ [42]. One of the most significant reasons for the increase of $\mathrm{HC}$ emissions is richer charge mixture. As the engine operates with the richer mixture the whole fuel cannot be oxidized [43]. Unburned $\mathrm{HC}$ emissions are formed as a result of incomplete combustion. Because ethanol has a lower cetane number and high heat of vaporization as explain in Table 1, it takes longer to vaporize which leads to longer ignition delay and short duration of combustion [44]. In addition, the engine needs more air in order to complete combustion in the HCCI combustion mode. Consequently, incomplete combustion occurs and $\mathrm{HC}$ emissions are formed.

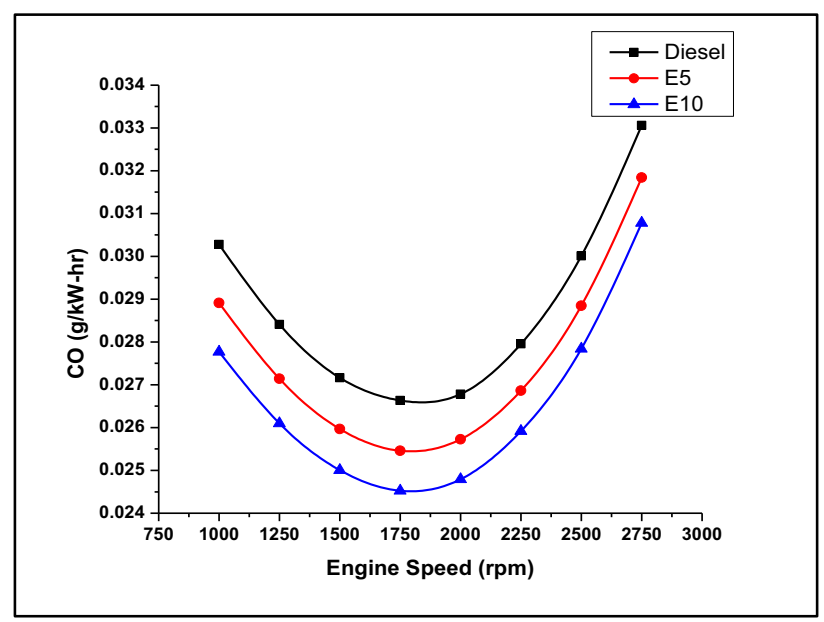

Figure 9. Carbon monoxide against engine speed

Carbon monoxide (CO) emission result is shown in Figure 9. The emission becomes higher with increased speed on the engine. The lowest $\mathrm{CO}$ valued achieved at1750 rpm for 3 types of fuels. From the figure it can be seen that as the percentage of ethanol in the blends increased the percentage of $\mathrm{CO}$ emission reduced. $\mathrm{CO}$ is an incomplete combustion product because of insufficient oxygen and temperature in the combustion chamber [45]. The emission reduced by dramatically as compared to diesel alone. This trend is due to the fact that ethanol has less carbon than diesel. Also, given the same fuel dispersion pattern as for diesel, the oxygen content in the blended fuels would help to increase the oxygen-to-fuel ratio in the fuel-rich regions. This resulting in more complete combustion leads to reduce of $\mathrm{CO}$ content in the exhaust smoke.

\section{References}

[1] Pidol L, Lecointe B, Starck L, Jeuland N. Ethanol-biodiesel-Diesel fuel blends: Performances and emissions in conventional Diesel and advanced Low Temperature Combustions. Fuel. 2012;93:329-38.

[2] Shahir SA, Masjuki HH, Kalam MA, Imran A, Ashraful AM. Performance and emission assessment of diesel-biodiesel- ethanol/bioethanol blend as a fuel in diesel engines: A review. Renewable and Sustainable Energy Reviews. 2015;48:62-78.

[3] Bendu H, Murugan S. Homogeneous charge compression ignition (HCCI) combustion: Mixture preparation and control strategies in diesel engines. Renewable and Sustainable Energy Reviews. 2014;38:732-46.

[4] Mohanamurugan S, Sendilvelan S. Emission and combustion characteristics of different fuel In A HCCI engine. International Journal of Automotive and Mechanical Engineering. 2011;3:279-92.

[5] Hairuddin A, Wandel A, Yusaf T. An introduction to a homogeneous charge compression ignition engine. Journal of Mechanical Engineering and Sciences. 2014;7:1042-52.

[6] Saxena S, Shah N, Bedoya I, Phadke A. Understanding optimal engine operating strategies for gasoline-fueled HCCI engines using crank-angle resolved exergy analysis. Applied Energy. 2014;114:155-63.

[7] Abdullah NR, Shahruddin NS, Mamat R, Ihsan Mamat A, Zulkifli A. Effects of air intake pressure on the engine performance, fuel economy and exhaust emissions of a small gasoline engine. Journal of Mechanical Engineering and Sciences. 2014;6:949-58.

[8] Yashwanth MS, Venugopal T, Ramesh A. Experimental and simulation studies to determine the effective octane number in an engine fuelled with ethanol and gasoline. International Journal of Automotive \& Mechanical Engineering. 2014;10.

[9] Stanglmaier RH, Roberts CE. Homogeneous charge compression ignition (HCCI): benefits, compromises, and future engine applications. SAE Technical Paper; 1999.

[10] Najafi G, Ghobadian B, Tavakoli T, Buttsworth D, Yusaf T, Faizollahnejad M. Performance and exhaust emissions of a gasoline engine with ethanol blended gasoline fuels using artificial neural network. Applied Energy. 2009;86:630-9.

[11] Yap D, Megaritis A, Wyszynski M. An investigation into bioethanol homogeneous charge compression ignition (HCCI) engine operation with residual gas trapping. Energy \& fuels. 2004;18:1315-23. 
[12] Tongroon M, Zhao H. Combustion characteristics of CAI combustion with alcohol fuels. 2010.

[13] Christensen M, Johansson B, Einewall P. Homogeneous charge compression ignition (HCCI) using isooctane, ethanol and natural gas-a comparison with spark ignition operation. SAE Technical Paper; 1997.

[14] Mack JH, Aceves SM, Dibble RW. Demonstrating direct use of wet ethanol in a homogeneous charge compression ignition (HCCI) engine. Energy. 2009;34:782-7.

[15] Viggiano A, Magi V. A comprehensive investigation on the emissions of ethanol HCCI engines. Applied Energy. 2012;93:277-87.

[16] Xie H, Wei Z, He B, Zhao H. Comparison of HCCI combustion respectively fueled with gasoline, ethanol and methanol through the trapped residual gas strategy. SAE Technical Paper; 2006.

[17] Li Y, Zhao H, Brouzos N. CAI combustion with methanol and ethanol in an air-assisted direct injection SI engine. 2008.

[18] Sjoberg M, Dec JE. Ethanol autoignition characteristics and HCCI performance for wide ranges of engine speed, load and boost. SAE Technical Paper; 2010.

[19] Splitter DA, Hanson RM, Reitz RD, Manente V, Johansson B. Modeling charge preparation and combustion in diesel fuel, ethanol, and dual-fuel PCCI engines. Atomization and Sprays. 2011;21.

[20] Hasan M, Rahman M, Kadirgama K. A review on homogeneous charge compression ignition engine performance using biodieseldiesel blend as a fuel. International Journal of Automotive \& Mechanical Engineering. 2015;11.

[21] De Nicolao G, Scattolini R, Siviero C. Modelling the volumetric efficiency of IC engines: parametric, non-parametric and neural techniques. Control Engineering Practice. 1996;4:1405-15.

[22] Saber HA, Al-Barwari RRI, Talabany ZJ. Effect of ambient air temperature on specific fuel consumption of naturally aspirated diesel engine. Journal of science and engineering: volume 1. 2013;1:1-7.

[23] Rajput R. A text book of Automobile Engineering: Firewall Media; 2007.
[24] Stotsky AA. Automotive engines: control, estimation, statistical detection: Springer Science \& Business Media; 2009.

[25] Hillier VAW, Coombes P. Hillier's fundamentals of motor vehicle technology: Nelson Thornes; 2004.

[26] Hairuddin AA, Yusaf T, Wandel AP. A review of hydrogen and natural gas addition in diesel HCCI engines. Renewable and Sustainable Energy Reviews. 2014;32:739-61.

[27] Guzzella L, Onder C. Introduction to modeling and control of internal combustion engine systems: Springer Science \& Business Media; 2009.

[28] Van Basshuysen R, Schäfer F. Internal combustion engine handbook-basics, components, systems and perspectives 2004 .

[29] Ganesh D, Nagarajan G. Homogeneous charge compression ignition (HCCI) combustion of diesel fuel with external mixture formation. Energy. 2010;35:148-57.

[30] Ebrahimi R, Ghanbarian D, Tadayon MR. Performance of an Otto engine with volumetric efficiency. J Am Sci. 2010;6:27-31.

[31] Menrad H, Nierhauve B. Engine and vehicle concepts for methanol-gasoline blends. SAE Technical Paper; 1983.

[32] Behçet R. Performance and emission study of waste anchovy fish biodiesel in a diesel engine. Fuel Processing Technology. 2011;92:1187-94.

[33] Lakshmi Narayana Rao G, Durga Prasad B, Sampath S, Rajagopal K. Combustion analysis of diesel engine fueled with jatropha oil methyl ester-diesel blends. International Journal of Green Energy. 2007;4:645-58.

[34] Puhan S, Vedaraman N, Sankaranarayanan G, Ram BVB. Performance and emission study of Mahua oil (Madhuca indica oil) ethyl ester in a 4-stroke natural aspirated direct injection diesel engine. Renewable Energy. 2005;30:1269-78.

[35] Swaminathan C, Sarangan J. Performance and exhaust emission characteristics of a CI engine fueled with biodiesel (fish oil) with DEE as additive. biomass and bioenergy. 2012;39:168-74.

[36] Heywood JB. Internal combustion engine fundamentals: Mcgraw-hill New York; 1988. [37] rahimi H, Ghobadian B, Yusaf T, Najafi G, Khatamifar M. Diesterol: An environment- 
friendly IC engine fuel. Renewable Energy. 2009;34:335-42.

[38] Gumus M, Sayin C, Canakci M. The impact of fuel injection pressure on the exhaust emissions of a direct injection diesel engine fueled with biodiesel-diesel fuel blends. Fuel. 2012;95:486-94.

[39] Gowthami K, Murali S, Reddy VN. Performance and analysis of super charging and blends of rice bran oil biodiesel as an additive in diesel-ethanol for diesel engines. 2014.

[40] Li L, Wang J, Wang Z, Xiao J. Combustion and emission characteristics of diesel engine fueled with diesel/biodiesel/pentanol fuel blends. Fuel. 2015;156:211-8.

[41] Li D-g, Zhen H, Xingcai L, Wu-gao Z, Jian-Guang Y. Physico-chemical properties of ethanol-diesel blend fuel and its effect on performance and emissions of diesel engines. Renewable energy. 2005;30:967-76.

[42] Lujaji F, Kristóf L, Bereczky A, Mbarawa M. Experimental investigation of fuel properties, engine performance, combustion and emissions of blends containing croton oil, butanol, and diesel on a CI engine. Fuel. 2011;90:505-10.

[43] Cinar C, Uyumaz A, Solmaz H, Sahin F, Polat S, Yilmaz E. Effects of intake air temperature on combustion, performance and emission characteristics of a HCCI engine fueled with the blends of $20 \%$ n-heptane and $80 \%$ isooctane fuels. Fuel Processing Technology. 2015;130:275-81.

[44] Yilmaz N, Vigil FM, Benalil K, Davis SM, Calva A. Effect of biodiesel-butanol fuel blends on emissions and performance characteristics of a diesel engine. Fuel. 2014;135:46-50.

[45] Cinar C, Uyumaz A, Solmaz H, Topgul T. Effects of valve lift on the combustion and emissions of a HCCI gasoline engine. Energy Conversion and Management. 2015;94:159-68. 